\title{
Neuropsychological investigations of the impulsive personality disorders ${ }^{1}$
}

\section{BACKGROUND}

There has been revived interest within the last few years in neuropsychological investigations of personality disorders (PDs) associated with impulsive and/or anti-social behaviour. Neuropsychological studies of such PDs offer two potential benefits: (i) an improving characterization of the cognitive and emotional difficulties experienced by individuals diagnosed with these disorders and, in particular, borderline PD and anti-social PD; (ii) the development of more precise hypotheses about the role of brain dysfunction in the aetiology and behavioural problems associated with these conditions. The most recent neuropsychological studies of impulsive PD have been interpreted against a background of accumulating evidence for structural (Driessen et al. 2000; Raine et al. 2000; Dolan et al. 2001), neurochemical (Coccaro \& Siever, 1995; Steinberg et al. 1997; Leyton et al. 2001) and functional brain abnormalities (Donegan et al. 2003). Future studies of impulsive PDs will be able to exploit advances in structural imaging (e.g. diffusion tensor imaging/tract mapping, e.g. Hoptman et al. 2002), as well as pharmacological and behavioural genetics (McGuffin \& Thapar, 1992; Lesch et al. 1996; Skodol et al. 2002).

Against these emerging opportunities need to be set the obstacles. Like similar research in psychiatric illnesses (e.g. Rogers \& Robbins, 2001), neuropsychological investigation of PD is complicated by significant clinical factors. First, there is the continuing debate about the validity of the diagnostic criteria used to identify particular PDs (e.g. Tyrer, 1999), as well variability between samples that probably arises through different methods of diagnosis (Kaye \& Shea, 2000). Recently, dimensional approaches to specifying personality disturbances have identified dysfunctional traits as part of a continuum of normality personality and also demonstrated that higher order clustering of these traits converges on several domains of impaired function specified by conventional categorical systems (Livesley et al. 1992, 1998). However, in general, neuropsychological studies in this area have continued to identify clinical samples in terms of DSM-III-R or DSM-IV Axis II (American Psychiatric Association, 1994), but supplemented this information with a dimensional measure of impulsivity.

Secondly, impulsive PDs tend to have markedly high rates of co-morbid AXIS I psychopathology (Skodol et al. 1999) as well as other forms of DSM-IV PDs (Skodol et al. 1999; Becker et al. 2000). Some of these disorders, e.g. depression (Elliott et al. 1996) and substance dependence (Rogers et al. 1999), are themselves associated with cognitive and emotional impairments that can be difficult to separate from those associated with the index PD. Finally, psychotropic medication and situational factors such as clinical samples interviewed in detention and control samples interviewed in the community have uncertain effects on motivation and neuropsychological task performance. It is unlikely that any one study could 'cover all of these bases'; as with investigations in other neuropsychiatric populations, comparison groups need to be selected to control factors of relevance to the particular cognitive or emotional functions targeted by investigators. Of course, these technical difficulties also affect methodologies used to investigate other biological factors in PD but they limit the interpretation of emerging neuropsychological data and will continue to do so even as

1 Address for correspondence: Dr Robert D. Rogers, Department of Psychiatry, University of Oxford, Warneford Hospital, Oxford OX3 7JX 
neuropsychological approaches are integrated more fully with brain imaging and pharmacological protocols.

In this commentary, I consider three studies recently published in Psychological Medicine. Two describe investigations involving samples of hospitalized offenders with antisocial traits (see Dolan \& Park, 2002; Dolan et al. 2002a) while the third study describes an investigation involving a sample characterized by borderline PD (see Bazanis et al. 2002). All three studies involve patient samples that are characterized by high levels of impulsivity chiefly manifested as either self-directed or outwardly directed aggression. In their different ways, these studies exemplify current trends in neuropsychological research with impulsive/antisocial PDs but point to important directions in which this kind of research needs to be developed over the next few years.

\section{FRONTAL LOBE/‘EXECUTIVE FUNCTION’ IN ANTISOCIAL PERSONALITY DISORDERS}

One continuing controversy is whether the antisocial PDs are associated with impairments in the so-called 'executive functions'. 'Executive functions' collectively mediate the dynamic organization of behaviour and permit us to use our cognitive resources in different ways to realize changing behavioural objectives. These functions include the ability to manipulate information in short-term memory, reorient our attention, and plan sequences of action to attain distal goals. There is convincing evidence that these functions depend, in large part, upon the integrity of the frontal lobes (Stuss, 2002). While there is little evidence that psychopathy - involving a propensity to an antisocial lifestyle combined with an emotional shallowness and absence of guilt (as characterized by the Psychopathy Checklist-Revised (Hare, 1991)) - is associated with impaired 'executive function' (Hart et al. 1990; see Blair \& Frith, 2000 for review), there have been reports of impairments in antisocial groups more broadly defined (e.g. Dinn \& Harris, 2000). One recent review concluded that 'executive function' is impaired in antisocial PD, with an estimated effect size of 0.62 (medium to large) (see Morgan \& Lilienfeld, 2000).

To examine the relationship between impaired 'executive function' in antisocial PD and impulsivity, Dolan et al. (2001a) administered a battery of neuropsychological tests focusing on predominantly frontal lobe tasks and also tested post-synaptic 5-hydroxytryptamine function as measured by the hormonal (prolactin) response to a D-fenfluramine challenge (Goodall et al. 1993). Personality disordered offenders from maximum-security psychiatric hospitals were characterized using the Special Hospital Assessment of Personality and Socialisation (SHAPS) (Blackburn, 1986) into those who were high impulsive and those who were low impulsive. The neuropsychological task performance and prolactin responses of these groups were compared with that of a group of nonoffender controls. All participants were screened for DSM-III-R Axis I illness, neurological illness or head injury, illicit drug use within the last 5 years, physical illness and prescribed psychoactive medication. Consistent with several previous studies (e.g. Coccaro et al. 1997), high impulsive offenders showed blunted prolactin responses to the D-fenfluramine challenge compared to low impulsive offenders, suggesting that increased impulsivity is associated with 5-HT abnormalities; in this study, the difference in prolactin response between the high impulsive offenders and the nonoffender controls was not significant. High impulsive offenders showed impaired 'executive function' (as measured by differences in composite $z$ scores of task performance) compared to both low impulsive offenders and controls. Memory function was not markedly affected. However, while impulsivity was associated with aggression, impulsivity itself was most closely associated with both level of performance on frontal lobe tasks and prolactin response. Therefore, these results suggest that impulsivity in anti-social individuals may be mediated by both impaired neuropsychological function - in particular, 'executive function' - and reduced 5-HT activity; as previously found, there also appears to be a rather more direct association between impaired neuropsychological function and aggression, probably also involving lowered IQ (Heilbrun, 1982).

More precise information about the nature of neuropsychological function in antisocial groups is provided by the second study considered here (Dolan \& Park, 2002). This study specifically involved 
offenders diagnosed with DSM-IV antisocial PD but no other AXIS II PD and who had been screened for current AXIS I disorder, previous drug or alcohol dependence, learning disability, medication and neurological damage. The tasks were selected as being putatively associated with both dorsolateral and ventromedial frontal lobe function, and included the Tower of London planning test (Owen et al. 1990) and a visual discrimination learning paradigm that tests the ability to shift an attentional bias or 'set' on the basis of feedback information (Owen et al. 1991). Both these cognitive activities are believed to depend upon activity within predominantly dorsolateral portions of the prefrontal cortex (Rogers et al. 2000). The battery also included a Go/No Go task in which participants were required to respond to $70 \%$ of visually presented stimuli but withhold responding to the remaining $30 \%$ of stimuli. It is likely that the inhibitory aspects of such tasks depend upon inferior portions of the frontal lobes (e.g. Aron et al. 2003). The final task was a delayed-matching-to-sample paradigm in which participants are shown a visual stimulus and, after a variable delay in which the stimulus is absent, required to select it from a display of four test stimuli (the target stimulus + three distractors). Delay-dependent deficits on this task are thought to indicate problems with recognition mnemonic processing mediated by inferior and medial temporal cortex (Mishkin, 1982; Owen et al. 1995).

Comparison with non-offender controls matched for age and IQ demonstrated that the antisocial PD offenders were impaired at formulating sequences of actions to solve problems on the Tower of London planning test, and that they were impaired at shifting a learnt attentional bias in visual discrimination learning. These two deficits are consistent with the proposal that antisocial PD involves dysfunction of circuitry encompassing the dorsolateral prefrontal cortex. The offenders also exhibited problems in the performance of the Go/No Go task, making consistently more errors of commission than the non-offender controls, and suggesting dysfunction in more inferior frontal areas as well. Finally, the antisocial PD offenders were consistently less accurate than controls at the delayed-matching-to-sample test. Since the deficit was as great at short delays as at long delays, it seems unlikely that this represents a purely mnemonic deficit and may instead represent some kind of attentional problem or difficulty with encoding the visual stimuli. Overall, these data demonstrate that a stringently screened sample of offenders identifiable as having diagnoses of DSM-IV antisocial PD but no other PD have a pattern of relatively widespread deficits on tasks involving predominantly frontal lobe function. They strengthen the evidence base for the proposal that antisocial PDs may involve alterations in frontally mediated cognition.

\section{IMPAIRED CHOICE ASSOCIATED WITH IMPULSIVITY IN BORDERLINE PERSONALITY DISORDER}

Our third paper examines neuropsychological function in the context of borderline PD. In contrast to antisocial PD, neuropsychological studies of borderline PD samples has been sporadic and limited in focus (O'Leary, 2000). There is some limited evidence that patients diagnosed with borderline PD exhibit a range of neuropsychological impairments. Specifically, deficits have been demonstrated on tasks involving attention, memory, visuospatial function, and emotional processing (O'Leary et al. 1991; Burgess, 1992; Judd \& Ruff, 1993; van Reekum, 1993; Kurtz \& Morey, 1999). However, these deficits have not been consistently replicated (see Driessen et al. 2000; Sprock et al. 2000). More recently, the focus has shifted to areas of cognition that appear most directly related to the specific symptomology of borderline PD. Dougherty et al. (1999) observed that female patients with borderline PD had difficulties tolerating delayed rewards compared to a nonpsychiatric controls. As described above, several studies have shown that antisocial groups are impaired at tasks that require some form of behavioural inhibition, and Leyton et al. (2001) have reported similar problems in borderline PD patients compared to healthy controls.

In the third paper considered here, Bazanis et al. (2002) investigated the performance of patients identified as having a history of impulsive aggression in the context of a diagnosis of borderline PD on a decision-making task involving choices between uncertain rewards and punishments. The task required participants first to predict which of two probabilistic events would occur and then, to 
decide how much they wished to gamble of their previously acquired reward on their prediction being correct. The task was structured in such a way as to separate risk-hunting versus risk-averse strategies of gambling and to discriminate both strategies from fast, premature responding that might reflect motor disinhibition. Previous research had shown that this task is impaired following focal damage to orbitofrontal areas but not dorsolateral or dorsomedial frontal areas (see Rogers et al. 1999). The patients were screened for current AXIS I psychopathology, current or previous psychotic illness, history of head injury, alcohol dependence or abuse within the previous 2 months.

Compared with healthy controls, borderline PD patients exhibited a pattern of delayed and maladaptive choices when choosing between probabilistic events, but markedly disinhibited responding when gambling on the outcome of their decisions. Notably, the delayed maladaptive choices of the borderline PD patients suggests that impulsivity in the context of these PDs is not always manifest as 'actions that appear poorly conceived, prematurely expressed ...' (Daruna \& Barnes, 1993) but may reflect a deeper cognitive deficit associated with resolving between competing courses of action. Similar effects have been observed in healthy volunteers selected for high levels of self-report impulsivity (Dickman, 1985). Bazanis et al. (2002) also administered a version of the Tower of London planning task (Owen et al. 1995) and found that the performance of the borderline PD patients was significantly impaired compared with controls and that, like the patients studied by Dolan \& Park (2002), the magnitude of impairment increased with problem complexity. Together, these data suggest that borderline PD is associated with brain dysfunction in orbitofrontal and dorsolateral regions of the frontal lobes, consistent with similar reports in individuals with the highly co-morbid antisocial PD (Dinn \& Harris, 2000; Dolan \& Park, 2002).

\section{CONCLUSION}

Collectively, these findings suggest that neuropsychological investigations can, in the context of careful clinical assessment, provide insights into altered cognitive and emotional processes associated with impulsive PDs. However, future research needs to meet two related challenges. First, it must demonstrate patterns of deficits that are specific to particular PDs. Currently, while there is increasing evidence that impulsive PDs are associated with neuropsychological deficits, there are virtually no data concerning whether these deficits are distinctive to one PD (or cluster of PDs) compared with other PDs (or cluster of PDs). Indeed, it is noteworthy that the clearest evidence of impairment in the three papers considered above involved comparisons between PD offenders/ patients and non-psychiatric healthy controls. Thus, demonstrating convincing differences between different clusters of PDs, or between different PDs and samples with relevant AXIS I illnesses (e.g. mood disorders in the case of borderline PD), and helping to delineate appropriate endophenotypes for other biological perspectives on PD (Siever et al. 2002), represents a rather stronger test for future research.

Secondly, future research needs to specify the relationships between cognitive and emotional deficits on the one hand and the symptomology of the PDs on the other hand. One way to meet this challenge will be to integrate properly different kinds of methodologies in order to establish how cognitive deficits in these disorders interact with other aspects of their pathophysiology. For example, recent research has suggested that altering 5-HT function in healthy volunteers can alter performance of the decision-making task used in Bazanis et al. (2002). Since there is now increasing evidence that 5-HT function is compromised in borderline PD (including the neuromodualtion of the prefrontal cortex; Soloff et al. 2000), we can test the hypothesis that the impaired decisionmaking associated with borderline PD involves altered neuromodulation of cognitive processes mediated by the prefrontal cortex. Currently, several international groups of PD researchers are now using brain-imaging technology to test such approaches formally. 


\section{REFERENCES}

American Psychiatric Association (1994). Diagnostic and Statistical Manual of Mental Disorders, 4th edn. American Psychiatric Association: Washington, DC.

Aron, A. R., Fletcher, P. C., Bullmore, E. T., Sahakian, B. J. \& Robbins, T. W. (2003). Stop-signal inhibition disrupted by damage to right inferior frontal gyrus in humans. Natural Neuroscience 6. 115-116.

Bazanis, E., Rogers, R. D., Dowson, J. H., Taylor, P., Meux, C., Staley, C., Nevison-Andrews, D., Taylor, C., Robbins, T. W. \& Sahakian, B. J. (2002). Neurocognitive deficits in decision-making and planning of patients with DSM-III-R borderline personality disorder. Psychological Medicine 32, 1395-1405.

Becker, D. F., Grilo, C. M., Edell, W. S. \& McGlashan, T. H. (2000). Comorbidity of borderline personality disorder with other personality disorders in hospitalised adolescents and adults. American Journal or Psychiatry 157, 2011-2016.

Blackburn, R. (1986). Patterns of personality deviation among violent offenders: replication and extension of an empirical taxonomy. British Journal of Criminology 26, 254-269.

Blair, R. J. \& Frith, U. (2000). Neurocognitive explanations of the antisocial personality disorders. Criminal Behaviour and Mental Health 10, S66-S81.

Burgess, J.W. (1992). Neurocognitive impairment in dramatic personalities: histrionic, narcissistic, borderline, and antisocial disorders. Psychiatry Research 42, 283-290.

Coccaro, E. F. \& Siever, L. J. (1995). The neuropsychopharmacology of personality disorders. Psychopharmacology: The Fourth Generation of Progress (ed. F. E. Bloom and D. J. Kupfer), pp. 1567-1579. Raven Press: New York.

Coccaro, E. F., Kavoussi, R. J., Cooper, T. B. \& Hauger, R. L. (1997). Central serotonin activity and aggression: inverse relationship with prolactin response to D-fenfluramine, but not CSF 5-HIAA concentration in human subjects. American Journal of Psychiatry 154, 1430-1435.

Daruna, J. H. \& Barnes, P. A. (1993). A neurodevelopmental view of impulsivity. In The Impulsive Client: Theory, Research and Treatment (ed. W. G. McCann, J. L. Johnson and M. B. Shire), pp. 76-89. American Psychological Association: Washington, DC.

Dickman, S. J. (1985). Impulsivity and perception: individual differences in the processing of local and global dimensions of stimuli. Journal of Personality and Social Psychology 48, 133-149.

Dinn, W. M. \& Harris, C. L. (2000). Neurocognitive function in antisocial personality disorder. Psychiatry Research 97, 173-190.

Dolan, M. \& Park, I. (2002). The neuropsychology of antisocial personality disorder. Psychological Medicine 32, 417-427.

Dolan, M. C., Anderson, I. M. \& Deakin, J. F. W. (2001). The relationship between 5-HT function and aggression in highly aggressive personality. British Journal of Psychiatry 178, 352-359.

Dolan, M., Deakin, W. J. F., Roberts, N. \& Anderson, I. (2002a). Serotonergic and cognitive impairments in impulsive aggressive personality disordered offenders: are there implications for treatment? Psychological Medicine 32, 105-117.

Dolan, M. C., Deakin, J. F., Roberts, N. \& Anderson, I. M. (2002b). Quantitative frontal and temporal structural MRI studies in personality-disordered offenders and control subjects. Psychiatry Research 116, 133-149.

Donegan, N., Sanislow, C. A., Blumberg, H. P., Fulbright, R. K., Lacadie, C., Skudlarski, P., Gore, J. C., Olson, I. R., McGlashan, T. H. \& Wexler, B. E. (2003). Amygdala hyper-reactivity in borderline personality disorder: implications for emotional dysregulation. Biological Psychiatry (in the press).

Dougherty, D. M., Bjork, J. M., Huckabee, H. C., Moeller, F. G. \& Swann, A. C. (1999). Laboratory measures of aggression and impulsivity in women with borderline personality disorder. Psychiatry Research 85, 315-326.

Driessen, M., Hermann, J., Stahl, K., Zwaan, M., Meier, S., Hill, A., Osterheider, M. \& Petersen, D. (2000). Magnetic resonance imaging volumes of the hippocampus and the amygdala in women with borderline personality disorder and early traumatization. Archives of General Psychiatry 57, 1115-1122.

Elliott, R., Sahakian, B. J., McKay, A. P., Herrod, J. J., Robins, T. W. \& Paykel, E. S. (1996). Neuropsychological impairments in unipolar depression: the influence of perceived failure on subsequent performance. Psychological Medicine 26, 975-989.

Goodall, G. M., Cowen, P. J., Franklin, M. \& Silverstone, T. (1993). Ritanserin attentuates anorectic, endocrine and thermic responses to D-fenfluramine in human volunteers. Psychopharmacology 112, 461-466.

Hare, R. D. (1991). The Hare Psychopathy Checklist-Revised. Multi-Health Systems: Toronto, Ontario.

Hart, S. D., Forth, A. E. \& Hare, R. D. (1990). Peformance of criminal psychopaths on selected neuropsychological tests. Journal of Abnormal Psychology 99, 374-379.

Heilbrun, A. B. (1982). Cognitive models of criminality based on intelligence and psychopathy levels. Journal of Clinical Psychology 50, 546-557.

Hoptman, M. J., Volavka, J., Johnson, G., Weiss, E., Bilder, R. M. \& Lim, K. O. (2002). Frontal white matter microstructure, aggression, and impulsivity in men with schizophrenia: a preliminary study. Biological Psychiatry 52, 9-14.

Hoffman Judd, P. \& Ruff, R. M. (2002). Neuropsychological dysfunction in borderline personality disorder. Journal of Personality Disorders 7, 275-284.

Judd, P. H. \& Ruff, R. M. (1993). Neuropsychological dysfunction in borderline personality disorder. Journal of Personality Disorders 7 , 275-284.

Kaye, A. L. \& Shea, M. T. (eds.) (2000). Personality Disorders, Personality Traits, and Defense Mechanisms. Handbook of Psychiatric Measures. American Psychiatric Association: Washington, DC.

Kurtz, J. E. \& Morey, L. C. (1999). Verbal memory dysfunction in depressed patients with and without borderline personality disorder. Journal of Psychopathology and Behavioural Assessment 21, $141-156$.

Lesch, K. P., Bengel, D., Heils, A., Sabol, S. Z., Greenberg, B. C., Petri, S., Benjamin, J., Muller, C. R., Hamer, D. H. \& Murphy, D. L. (1996). Association of anxiety related traits with a polymorphism in the serotonin transporter gene regulatory region. Science 274, 1527-1531.

Leyton, M., Okazawa, H., Diksic, M., Paris, J., Rosa, P., Mzengeza, S., Young, S. N., Blier, P. \& Benkelfat, C. (2001). Brain regional $\alpha-\left[{ }^{11} \mathrm{C}\right]$ methyl-L-tryptophan trapping in impulsive subjects with borderline personality disorder. American Journal of Psychiatry 158, 775-782.

Livesley, W. J., Jackson, D. N. \& Schroeder, M. L. (1992). Factorial structure of traits delineating personality disorders in clinical and general population samples. Journal of Abnormal Psychology 101, 432-440.

Livesley, W. J., Jang, K. L. \& Vernon, P. A. (1998). Phenotypic and genetic structure of traits delineating personality disorder. Archives of General Psychiatry 55, 941-948.

McGuffin, P. \& Thapar, A. (1992). The genetics of personality disorder. British Journal of Psychiatry 160, 12-23.

Mishkin, M. (1982). A memory system in the monkey. Philosophical Transactions of the Royal Society London Biological Science $\mathbf{2 9 8}$ 85-92.

Morgan, A. B. \& Lilienfeld, S. O. (2000). A meta-analytic review of the relation between antisocial behavior and neuropsychological measures of executive function. Clinical Psychological Review 20, 113-136.

O'Leary, K. M. (2000). Neuropsychological testing results in borderline personality disorder. Psychiatric Clinics of North America 23, 41-60.

O’Leary, K. M., Brouwers, P., Gardner, D. L. \& Cowdry, R. W. (1991). Neuropsychological testing of patients with borderline personality disorder. American Journal of Psychiatry 148, 106-111.

Owen, A. M., Downes, J. J., Sahakian, B. J., Polkey, C. E. \& Robbins, T.W. (1990). Planning and spatial working memory following frontal lobe lesions in man. Neuropsychologia $\mathbf{2 8}$ $1021-1034$ 
Owen, A. M., Roberts, A. C., Polkey, C. E., Sahakian, B. J. \& Robbins, T. W. (1991). Extra-dimensional set shifting peformance following frontal lobe excisions, temporal lobe excisions or amygdalo-hippocampectomy in man. Neuropsychologia 29, 993-1006.

Owen, A. M., Sahakian, B. J., Semple, J., Polkey, C. E. \& Robbins, T.W. (1995). Visuo-spatial short term recognition memory and learning after temporal lobe excisions, frontal lobe excisions or amygdalo-hippocampectomy in man. Neuropsychologia $\mathbf{3 3}$, $1-24$.

Raine, A., Lencz, T., Birhle, S., LaCasse, L. \& Colleti, P. (2000). Reduced prefrontal gray matter and reduced autonomic activity in antisocial personality disorder. Archives of General Psychiatry 57, 119-129.

Rogers, R. D. \& Robbins, T. W. (2001). Investigating the neurocognitive deficits associated with chronic drug misuse. Current Opinions in Neurobiology 11, 250-257.

Rogers, R. D., Everitt, B. J., Baldacchino, A., Blackshaw, A. J., Swainson, R., Wynne, K., Baker, N. B., Hunter, J., Carthy, T., Booker, E., London, M., Deakin, J. W. F., Sahakian, B. J. \& Robbins, T. W. (1999). Dissociating deficits in the decisionmaking cognition of chronic amphetamine abusers, opiate abusers, patients with focal damage to prefrontal cortex, and tryptophan-depleted normal volunteers: evidence for monoaminergic mechanisms. Neuropsychopharmacology 20, 322-329.

Rogers, R. D., Andrews, T. C., Grasby, P. M., Brooks, D. \& Robbins, T. W. (2000). Contrasting cortical and sub-cortical PET activations produced by reversal learning and attentionalset shifting in humans. Journal of Cognitive Neuroscience 12, $1-21$.
Siever, L. J., Torgesen, S., Gunderson, J. G., Livesley, W. J. \& Kendler, K. S. (2002). The borderline diagnosis III: identifying endophenotypes for genetic studies. Biological Psychiatry 51, 964-968.

Skodol, A. E., Stout, R. L., McGlashan, T. H., Grilo, C. M Gunderson, J. G. \& Shea, M. T. (1999). Co-occurrence of mood and personality disorders: a report from the Collaborative Longitudinal Personality Disorders Study (CLPS). Depression and Anxiety 10, 175-182.

Skodol, A. E., Siever, L. J., Livesley, W. J., Gunderson, J. G., Pfohl, B. \& Widiger, T. A. (2002). The borderline diagnosis II: biology, genetics and clinical course. Biological Psychiatry 51, 951-963.

Soloff, P. H., Meltzer, C. C., Greer, P. J., Constantine, D. \& Kelly, T. M. (2000). A fenfluramine-activated FDG-PET study of borderline personality disorder. Biological Psychiatry 47, 540-547.

Sprock, J., Rader, T. J., Kendall, J. P. \& Yoder, C. Y. (2000) Neuropsychological functioning in patients with borderline personality disorder. Journal of Clinical Psychology 56, 1587-1600.

Steinberg, B. J., Trestman, R., Mitropoulou, V., Serby, M., Silverman, J., Coccaro, E., Weston, S., de Vegvar, M. \& Siever, L. J. (1997). Depressive response to physostigmine challenge in borderline personality disorder patients. Neuropsychopharmacology 17, 264-273.

Stuss, R. D. (2002). Principles of Frontal Lobe Function. Oxford University Press: Oxford.

Tyrer, P. (1999). Borderline personality disorder: a motley diagnosis in need of reform. Lancet 354, 2095-2096.

van Reekum, R. (1993). Acquired and developmental brain dysfunction in borderline personality disorder. Canadian Journal of Psychiatry 38 (suppl.), 84-90. 